\title{
Phase coexistence in fluidization
}

\author{
Feng $\mathrm{Lu}^{1}$, Chenxi Zhang ${ }^{1}$, Yao Wang ${ }^{1}$, Weizhong Qian ${ }^{1}$, and Fei Wei ${ }^{1}$ \\ ${ }^{1}$ Tsinghua University
}

May 18, 2021

\begin{abstract}
The coexistence of granular liquid-like phase (cluster) and gas-like phase (void) in fluidization, a spontaneous symmetrybreaking dissipative state, contributes to excellent mixing behavior in multi-phase reactors. In present study, a universal granular state equation to describe phase coexistence far from critical point is developed, where both the inelastic solid-collision and asymmetrical instability is taken into consideration. Catastrophe theory is applied to find the stable boundary of phase coexistence, and verified by cold-flow experiment with different solid pressure. A phase diagram, based on both theoretical analysis and experimental study, is given as a useful guideline of design and operation of efficient multi-phase reactors.
\end{abstract}

\section{Hosted file}

Main Document-Phase coexistence in fluidization-submit.pdf available at https://authorea.com/ users/414300/articles/522367-phase-coexistence-in-fluidization
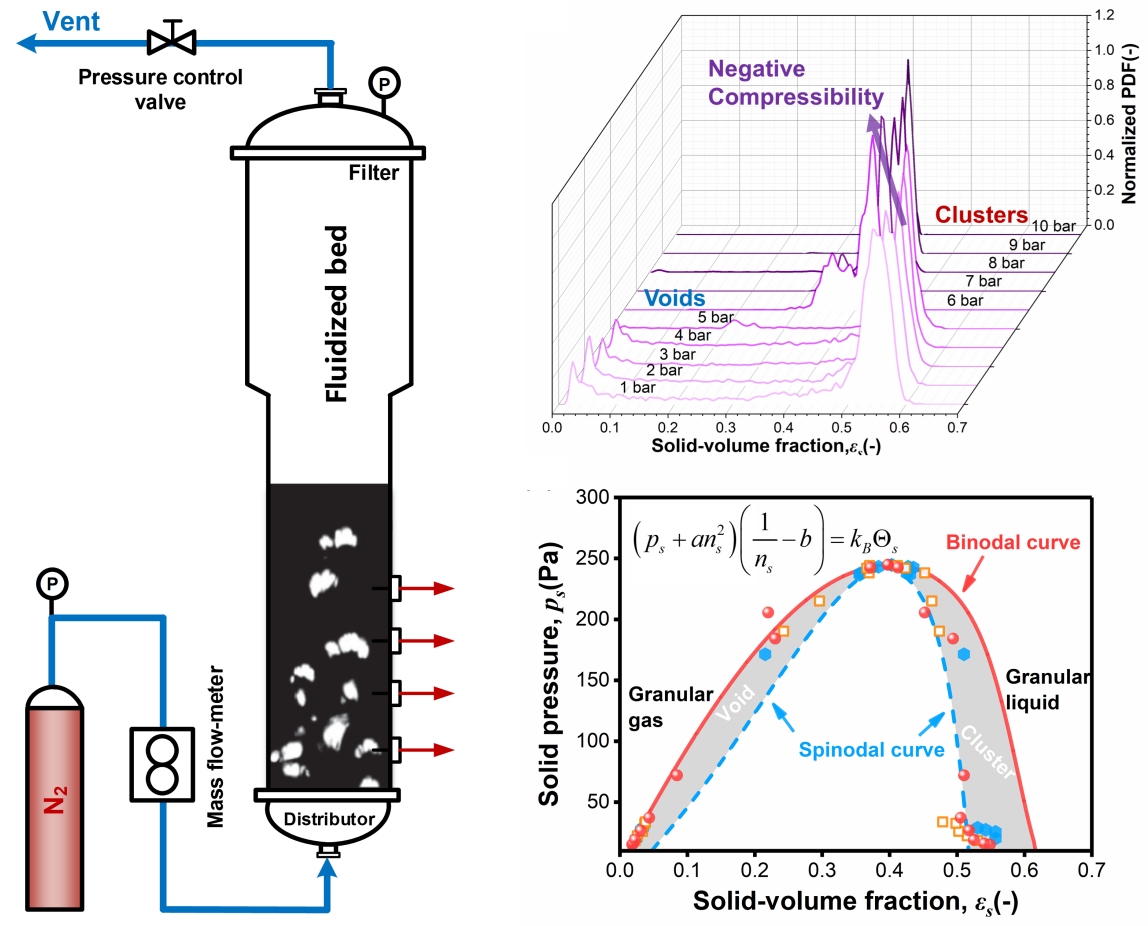
(a)
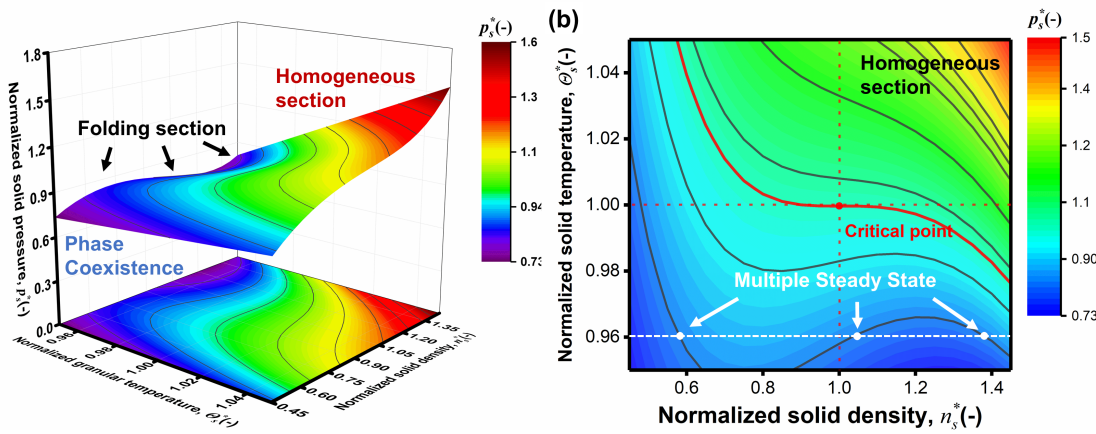

(a)

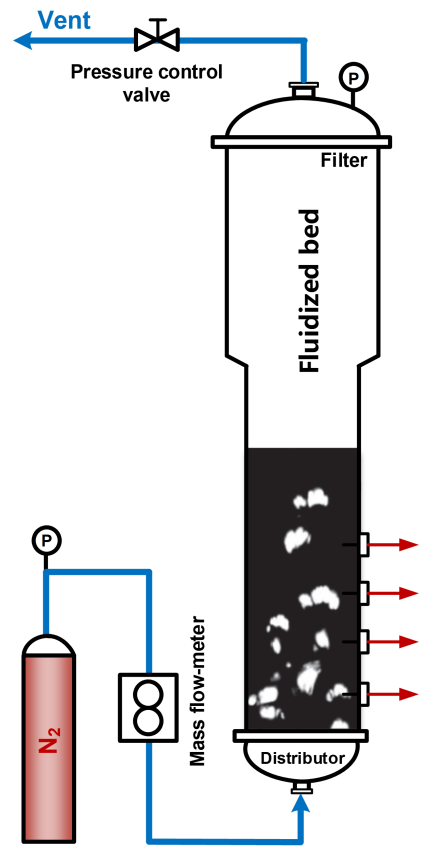

(b)

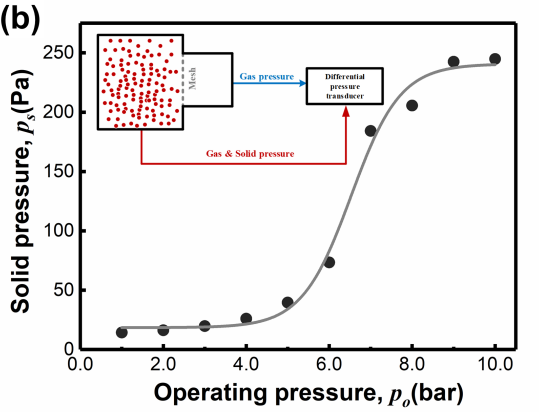

(c)

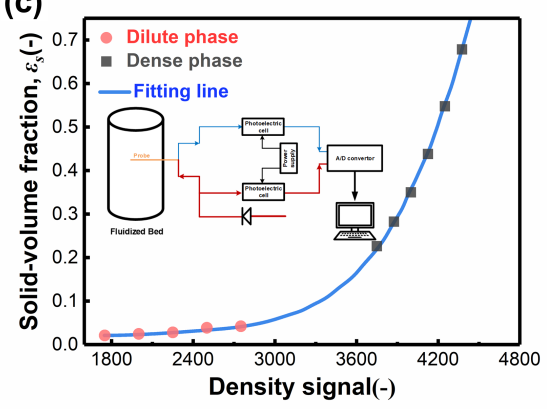

(a)

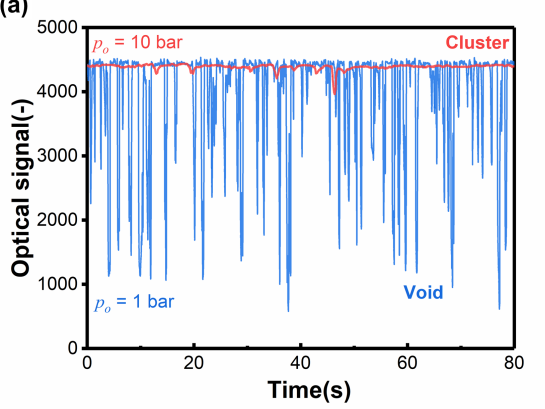

(b)

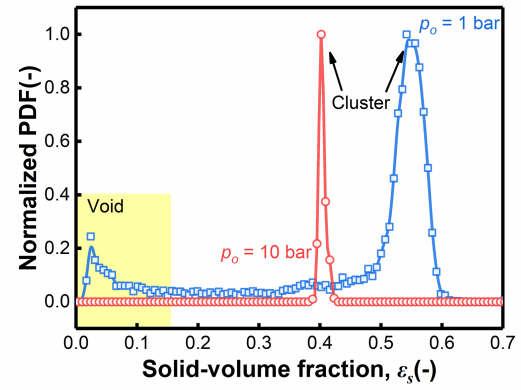


(a)

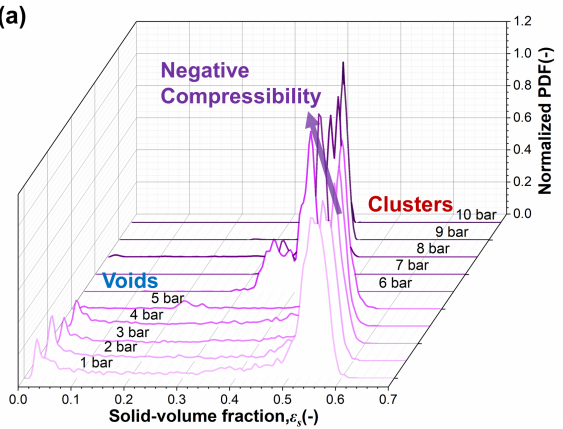

(b)

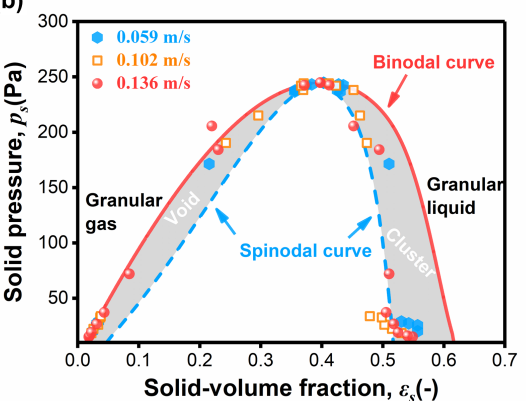

